\title{
Bordando o manto do mundo: o surrealismo e o nome das coisas
}

$\frac{\text { MaYra Rodrigues Gomes }}{\text { Escola de Comunicações e Artes/ECA-USP }}$ 


\section{Resumo}

Este texto evoca o trabalho do surrealismo sob o ponto de vista de seu jogo com as palavras, as imagens e as coisas, trabalho que mostra a condição imaginária da realidade vivida.

Palavras-chave

realidade, estratificações, imaginário

\section{Abstract}

This paper evokes surrealistic works from the view point of its game with words, images and things, work that shows the imaginary condition of our experienced reality.

\section{Key words}

reality, stratifications, imaginary 
Ao Professor Eduardo Peñuela Cañizal. $O$ brilho de suas aulas em débito ao de sua pessoa. Pequeno texto, dedicado a um grande mestre.

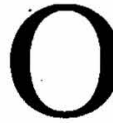

legado amplo do movimento surrealista é freqüentemente remetido a um ponto inaugural: nos Manifestos do Surrealismo, de André Breton. O plural do título é resposta à apresentação de dois contornos do movimento: um em 1924, outro em 1930.

O primeiro leva em conta conceitos da psicanálise e é centrado na idéia de automatismo psíquico, pelo qual as expressões estariam livres do controle da razão, livres de constrições morais e estéticas. O segundo reforça a tomada de um enfoque com o qual as habituais dicotomias, tais como real e imaginário, não mais seriam vistas em contradições.

Os dois manifestos, num conjunto que encerra mais do que foi acima exposto, dão conta das diversas facetas do movimento. Contudo, o segundo enfoque tende a neutralizar o papel do automatismo psíquico, pois nos remete a um trabalho específico do surrealismo, trabalho que dá prioridade à reflexão e nutre alguns conceitos e teorias que the fazem pano de fundo. Gostaríamos de explorar, exemplificando, um dos vários modos com o qual o surrealismo dá espaço a este viés. Tomaremos, como ponto de exercício, a pintura surrealista e seu constante jogo com os nomes das coisas, jogo que trabalha a injunção real/imaginário e aponta para a tessitura em que se sustenta nossa humana constituição.

Conceitos e teorias se compõem mutuamente, assim como as dicotomias que o surrealismo procura mostrar em complementaridade. Naturalmente, o mais afamado jogo entre as 


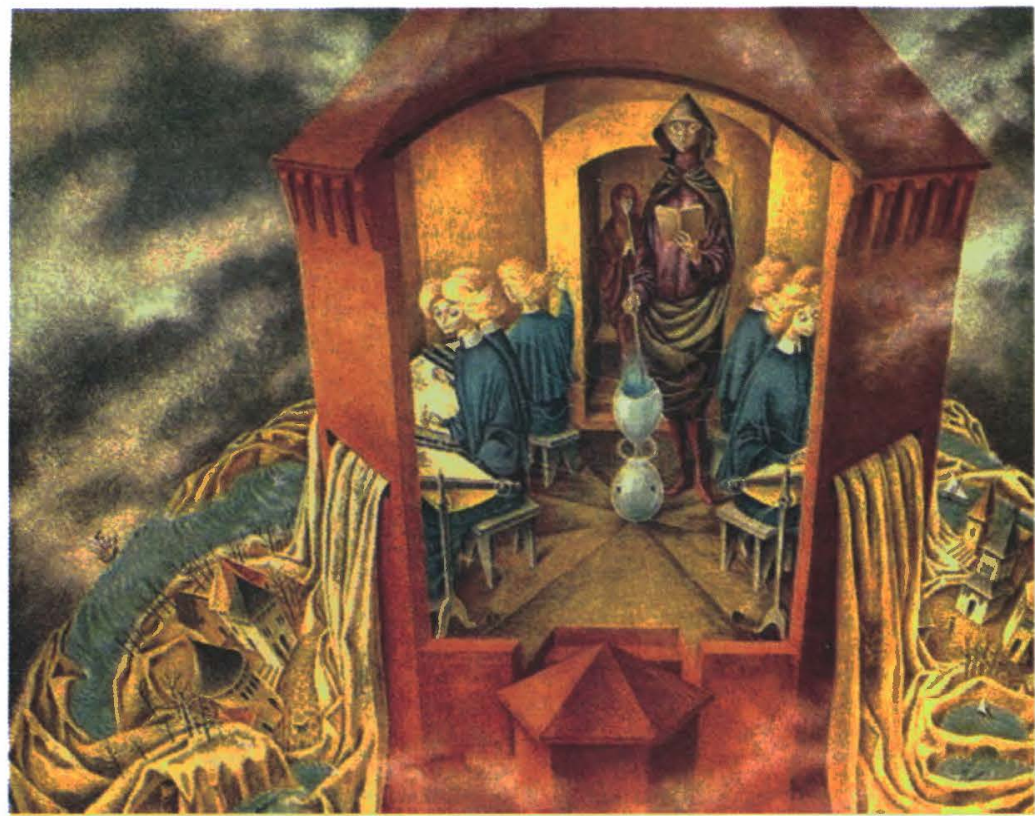

Bordando el manto terrestre - Remedios Varo, 1961.

palavras, as imagens e as coisas pode ser visto na obra de Renné Magritte, particularmente no quadro, bastante conhecido, em que a escrita verbal se inscreve na própria imagem. Trata-se do trabalho Trahison des images (1929), em que, sob a pintura de um cachimbo, estão escritas/desenhadas as palavras Ceci n'est pas une pipe. Traição das imagens e traição das palavras, enquanto pensadas como correlatas a seus referentes. A alusão à constituição dos signos, imagéticos ou verbais, fez desse quadro uma citação corrente em tratados de semiótica. Nesse caso, ele serve de demonstração para uma condição sígnica básica, a saber, a distância (ou diferença) intransponível entre representação e representado, entre signo e referente.

Nesse quadro, a obra de arte é desviada do estatuto representação/semelhança. Como tal estatuto se firma sobre a relação entre referente e signo, esta é deslocada do vetor realismo, a saber, a aproximação com maior fidelidade da representação ao representado, para ser colocada como criação. 
No jogo entre palavra e imagem que o quadro comporta, resume-se uma tomada teórica que nos conduz ao entendimento do universo, enquanto instância à qual temos acesso somente como inscrição, ou seja, enquanto instância organizada/produzida pela via da simbolização, como realidade construída, como, ao invés de representação, uma "apresentação do mundo".

Naturalmente, para que essa construção se institua como realidade, é preciso que sua condição de construto seja esquecida. Sua dimensão mítica, nas mais simples situações, tem que ser obliterada. Se assim não o fosse, se não houvesse o esquecimento, perguntaríamos, por exemplo, o que realmente contém este isolamento de campo suposto pela palavra estresse; perguntaríamos a todo instante, a ponto de perguntar se ela, a palavra, realmente é correlata a alguma coisa impecavelmente delineada.

Em seu jogo, o surrealismo não nos deixa esquecer das condições da ordem simbólica e da exata implicação que uma dicotomia, como esta entre referência e referente, supõe: o esquecimento da sustentação das relações entre os termos, eles próprios elementos desta ordem que institui o mundo.

Neste ponto, outra obra do pintor permite o mesmo tipo de exploração. $\mathrm{O}$ quadro mostra parte de uma porta, fechadura em close que revela, do lado de lá de seu buraco, um céu azul com nuvens claras - o céu de Magritte - onde paira uma chave dourada. Título:: Le sourire du diable (1966).

Há referências explícitas por parte do pintor, em correspondência mantida com seu marchand, ao conceito de absoluto. Ora, tal conceito nos remete à idéia de completude, de essencialidade, de sentido e, portanto, de respostas. Este sorriso do diabo, que como se sabe é sempre irônico e fino, e esta chave do lado de lá nos dizem que as respostas não se encontram ao alcance, embora possam ser prometidas como transcendência. Não importa o que se faça ou se diga: essencialidades não estão à mão.

Como pano de fundo identifica-se uma teoria da representação que compreende bem a clivagem entre signo e referente (porque as respostas inequívocas dependem da não-clivagem), um entendimento da palavra com uma dimensão que lhe é própria, entendimento 
que impele Drummond a incitar: "Chega mais perto e contempla as palavras. Cada uma tem mil faces secretas sob a face neutra e te pergunta, sem interesse pela resposta, pobre ou terrivel que lhe deres: Trouxeste a chave?". Naturalmente que o surrealismo em toda sua produção, e por meio deste quadro de Magritte dá a resposta terrível, em consonância com seus propósitos de rompimento com uma prática estabelecida.

Embora nesta seqüência estejamos ainda lidando com uma certa teoria da representação, melhor dito, de apresentação, algo mais vasto se introduz agora. Como pensamento de seu tempo, e Breton faz questão de enunciá-lo, a presença de conceitos expostos pela psicanálise, calcados nas propostas do estruturalismo, é marcante.

É o que podemos perceber diante do quadro de um cavalete, postado contra uma janela que se abre para a paisagem campestre, sobre o qual repousa uma tela, outro quadro, tela cuja paisagem se mescla à paisagem emoldurada pela janela, estamos no limite, limite da reflexão teórica, limite onde o surrealismo se inscreve.

Ao olharmos para este quadro podemos conjeturar novamente sobre as representações, sobre as fronteiras tênues, indiscerniveis, entre representante e representado, ao mesmo tempo sobre a distância entre ambos, e sobre a verossimilhança, e sobre o simulacro...Mas não é isto, embora também isto, que está em questão.

Olhemos novamente para as palavras, para o nome das coisas. Este quadro tem um nome: La condition humaine (1934). Magritte o utiliza em telas similares. Nelas, sempre um anteparo que se confunde com a paisagem ao fundo; entre anteparo e paisagem a condição humana. Estamos no seio da grande trilogia estruturalista: o Real, o Simbólico e o Imaginário. É esta relação, da trilogia e do surrealismo com a trilogia, que tentaremos explorar.

Nossa exploração começa pelas palavras e tal começo tanto mais faz sentido quanto o trabalho desses quadros, sobre conceitos e teorias, fica explícito na conversa mantida entre obra e seu título.

Quando nomeamos, apontamos para algo através de uma palavra, assim permitindo sua existência em outras esferas, outros tempos e lugares, além de aqueles de sua atribuição originária. É 
assim que podemos conversar, aqui, sobre as gigantescas tartarugas da Polinésia (que nunca vimos), sobre a polêmica dos universais (da qual jamais participamos, ao menos em seu tempo), sobre os dragões chineses (sem saber de sua existência ou consistência) e, naturalmente, sobre as personagens de nossa bagagem teórica, nas suas marchas e contramarchas em direção às idéias que partilhamos ou deixamos de partilhar.

Esta propriedade - fundadora dos processos de abstração que nos permitem pensar/falar sobre as coisas - que é atribuição simbólica e nos instituiu enquanto espécie diferenciada das outras, recobre instâncias mais cruciais que nos autorizam o uso, para ela, da terminologia ordem.

Trata-se do fato de que nomear é isolar um campo, instituindo o modo de ser e, por vezes, até a própria existência. É por diferenciação que o fazemos, em imediata oposição e similaridade entre elementos. Assim, dentre as pedras preciosas, as selecionamos por agrupamento de características semelhantes, embora elas jamais sejam iguais. Tal operação depende, para sua efetivação, de um nome que se acople e marque o isolamento de campo. O diamante, e sua dureza, desdobra-se nas cores e formas em que ele pode ser encontrado, ou burilado, formas jamais coincidentes, cores jamais repetidas. O nome e a dureza permanecem como ponto nevrálgico, apagando o fato de que o recorte feito, o isolamento de campo, sempre poderia ter sido segundo outros critérios e outros nomes, em suma, ter sido outro. A mesma lógica se aplica à palavra: estresse, que mencionamos anteriormente.

Ora, o que tal recorte realmente implica, do estresse ou do diamante, é a apresentação de mundo: veja esta pedra; observe: ela é assim e assado e é realidade do mundo. Mas, não é só uma questão do olhar, como se isso já não bastasse, que faz emergir uma existência. É, sobretudo, a existência revelada de um certo modo que a torna criação do objeto, ao invés de correlação.

Os recortes se naturalizam numa apresentação. Talvez isto fique bem mais claro se pensarmos a medicina galênica e sua classificação das funções e disfunções por humores, classificação certamente bem distante da que temos hoje em dia e que se sustenta 
em tipos de disfunções orgânicas: a ineficácia de um órgão. Talvez isto fique ainda mais claro se pensarmos, como o fez Michel Foucault, sobre o nascimento, no século XIX, da palavra homossexual: com ela, onde antes havia um hábito, tem-se agora uma espécie.

Claro que o dado material, ou o evento no mundo, ai se encontra de antemão: fato inegável ao menos para os dois últimos exemplos. O que é contestável é que ele seja sempre visto, sem que o isolamento de campo, ou o recorte simbólico, se efetue. Ainda é contestável que ele exista sempre de uma única maneira, a saber, que o modo como o apreendemos esteja em perfeita equivalência àquilo que ele é na materialidade do mundo. A historicidade implicada nos dois últimos exemplos também nos dá respaldo nesta asserção. Trata-se, portanto, de uma organização do dado a ver e, conseqüentemente, das formas com as quais vivenciamos o mundo, o que nos autoriza a menção a uma ordem simbólica.

O poder simbólico é um poder de construção da realidade que tende a estabelecer uma ordem gnoseológica: o sentido imediato do mundo (e, em particular, do mundo social) supõe aquilo a que Durkheim chama o conformismo lógico, quer dizer, 'uma concepção homogênea do tempo, do espaço, do número, da causa, que torna possivel a concordância entre as inteligências'. (Bourdieu, 2001, p. 9)

Até aqui conseguimos mostrar existência e modos como produtos de isolamentos sobre um campo material. Mas, se não fizermos o percurso da própria existência, não conseguiremos mostrar o peso da ordenação que o simbólico comporta.

Quando falamos sobre os deuses, sobre a magia, sobre o campo místico em geral, sempre colocamos a questão em sua imaterialidade e, por conseguinte, em sua submissão a um ato de fé. Com isso, escamoteamos o princípio das coisas e perdemos de perspectiva as implicações do simbólico. Ao falarmos em fadas, duendes e unicórnios, a coisa mais 'secundária é se eles existem em materialidade ou não, ou se eles existem para os que crêem e não existem para os que não crêem. 
Importa compreender que crentes ou não crentes, por deles falarmos, sua existência é definitivamente atestada justamente na dimensão específica do humano: a fala. No simbólico, a existência emerge como efeito do próprio simbólico: quer seja a do diamante, como o compreendemos, ou a das fadas, como as concebemos.

Mas, se ainda nos ativermos a este papel de criação/apresentação do mundo de novo nos escapará a compreensão mais aproximada. Trata-se de uma operação implicada nessa apresentação e que consiste na organização do que devemos vivenciar como do mundo, pois estas colocações no simbólico não se fazem sem que uma administração das situações vividas esteja suposta, seja essa administração manifesta numa oferenda aos deuses ou no uso instrumental, na criação de artefatos possíveis a partir dos dados enunciados.

Tentemos, à guisa de teste, questionar a materialidade do saci, ou seja, se ele existe ou não. Podemos fazê-lo em função desta existência que ele adquire nas palavras e que nos autoriza a falar sobre ele. Nesse caso, desembocamos na existência anteriormente constatada. Podemos fazê-lo em função desta existência que ele adquire ao representar uma perspectiva, um olhar de mundo. Contudo, ainda podemos conduzir este questionamento de outro ponto de vista, do ponto de vista dos efeitos. É como efeito que nos lembraremos das cozinhas que se preparavam contra suas artimanhas através de fantasiosas estratégias, como a colocação de um peso sobre as tampas das panelas para dificultar a manipulação pelo arteiro. Com certeza sua fisicalidade torna-se, agora, absolutamente secundária e o saci é bastante consistente: existente.

No ponto de chegada ao saci, ou ao unicórnio, às fadas, aos duendes etc. aproximamo-nos da questão dos conceitos e de sua imaterialidade, sempre secundária se levarmos em conta seu efeito de real.

Assim, podemos falar da ordem simbólica, que consiste em organizar o mundo dizendo-nos, ao diferenciar as partes, de como ele pode ou deve ser visto, e, a partir disso, delineando linhas de conduta, tomadas estratégicas face a esta visão. A ordem simbólica nos apresenta o a ser visto, experimentado, vivido: tanto os modos quanto as existências. $O$ resto é silêncio. 
É por ignorar que a ordem consiste numa condição originária do simbólico, que ela persiste como função co-extensiva em toda comunicação, em toda produção humana, surrealismo incluso, que nos confundimos nas atribuições do imaginário, assunto que sempre retorna quando nos postamos na fronteira das representações.

É necessário considerarmos, como fizemos até agora, que um termo faz um recorte de campo, constituindo o dado pela enunciação, portanto, apresentando-o como realidade do mundo. Nesse passo o mundo é desenhado, nesse desenho o humano edificado. Os indivíduos são formados, possuídos pelas formas simbólicas que o definem, a tal ponto que a própria concepção de sujeito, predominante em nossa contemporaneidade, incorporando estas considerações, passou a colocá-lo em conformidade às diferentes visadas de mundo, no limite, ao surgimento e ao desaparecimento. $O$ sujeito é sempre uma derivada. Ele nasce e se esvai na espessura do que se diz, do que se vê. (Deleuze, 1998a, p.134)

As diferentes estratégias educacionais certamente nos apontam para estas diferentes visadas do homem. Por exemplo, o homem é bicho traiçoeiro e somente quando submetido a rígidos treinamentos pode ser levado a uma superação; ou é bom em sua origem e esta deve ser recuperada; ou só é bom na potencialização de suas qualidades que devem ser estimuladas...

Nesse caso, se pensarmos o dado do mundo como dado de enunciação, como efeito de enunciados, a realidade assim constituída é imaginária, caso queiramos contrapô-la à materialidade do mundo. Foi pela não distinção entre simbólico e imaginário, enquanto esta indistinção foi pensada como "um jogo de espelhos entre real e imaginário", como se o real nos aparecesse sem a mediação do simbólico, que o poder da ordem simbólica pode passar despercebido. Por outro lado, se antagonizarmos simbólico e imaginário, perderemos de vista, novamente, a dimensão da força, a dimensão da ordem que é ao mesmo tempo simbólica e imaginária, força de uma que não se faz sem a outra.

$\mathrm{Se}$, como dissemos anteriormente, os processos simbólicos se constituem numa ordem que isola, diferencia, organiza um campo e funda as bases de sua administração, de forma tal que 
palavras de ordem e dispositivos disciplinares manifestam-se como sua imediata correlação, estas operações e efeitos não são concretizáveis sem que haja uma série de significações atribuídas ao isolamento de campo instalado. Tais significações se comporão com a ordem, que é sempre de natureza sistêmica, de modo a formar um conjunto. Mas, tanto significações quanto conjuntos são de natureza imaginária se os pensarmos como criação/apresentação do mundo.

Mas é precisamente aqui que passa a fronteira entre o imaginário e o simbólico: o imaginário tende a refletir $e$ a agrupar em cada termo o efeito total de um mecanismo de conjunto, enquanto a estrutura simbólica assegura a diferenciação dos termos e a diferenciação dos efeitos. (Deleuze, 1995, p.272)

Talvez consigamos depurar a questão explorando o termo estresse, uma última vez, através de algumas perguntas simples. Existe realmente algo que possa ser inequivocamente entendido como tal? Que circunscrição de campo é feita pelo termo? O que ele significa? Que sentidos são com ele criados? A que se presta uma tal designação? A quem ela interessa?

As respostas, todas elas concebíveis a partir de uma administração do campo isolado pela palavra, calcadas em vetores gnosiológicos, sociais, políticos e mercadológicos, conduzem-nos a uma invenção. Já se vê então, que nossa concepção de imaginário não se encontra em oposição à realidade: ela é constitutiva da realidade vivida; nem se opõe ao real pensado como materialidade e acontecimento: o sentido inventado incide sobre essas instâncias; tampouco se opõe ao simbólico: ao contrário, é seu efeito imediato.

Esse mundo, concebido como um todo, com tudo aquilo que este termo comporta, qualquer que seja a abertura que lhe dêem, delimitado, continua sendo uma concepção - é mesmo esta palavra - uma vista, um modo de olhar, uma tomada imaginária. (Lacan, 1985, p. 60) 
Uma ordem imaginária é a outra face da ordem simbólica. Mas, podemos ver que este termo tem aí uma aplicação especial e que a ele, normalmente, não se associa a palavra ordem. Devemos então explicar a concepção de imaginário aqui apresentada e que foi pensada, inicialmente, pelo estruturalismo. $\mathrm{Da}$ origem do termo a algumas de suas aplicações correntes, é necessário um pequeno trajeto para que fique bem compreendida a extensão da força dessa face, força que nos permitirá mostrar seu papel ordenador.

A noção corrente do imaginário sempre remete a fictício, a simulacro enquanto empobrecimento da realidade, pois a imaginação, seu reduto, encontra-se definida em relação a uma materialidade da qual advém. É nesse sentido que Sherlock Holmes sempre pôde referir-se às interpretações dadas por Watson aos fatos, como figmentos de imaginação, uma vez que não se prendem ao dado empírico.

Ora, já ficou patente que compreendemos o imaginário de outro modo. Tal compreensão como significância do recorte operado pelo simbólico, o imaginário, como contrapartida ao simbólico, vem numa acepção bem moderna que tem sua apresentação específica no século XX e, na verdade, comporta diversas faces.

Tal acepção nos remete a vários pensadores que a introduziram e exploraram. Nenhum deles teve as mesmas motivações, tampouco os mesmos pressupostos. De forma tal que o conjunto de suas reflexões encontra-se em oposição, às vezes foi a própria oposição que gerou suas escrituras. Discorrer sobre tais conflitos certamente nos levaria a mais de um artigo. No entanto, em referência ao imaginário, eles se cruzam, olham o mesmo evento de ângulos diferenciados e formam um quadro geral em que um vem compor com o outro e recobrir a perspectiva que foi deixada de lado. Pagaremos tributo a esses senhores e atravessaremos seus escritos desconsiderando suas ocasionais, às vezes imensas, diferenças.

Lacan delineou uma trilogia, o Real, o Simbólico e o Imaginário, com a qual temos uma espécie de gênese do humano e do mundo como por este vivenciado. Ao Real corresponde a noção de caos concebida pelos gregos: um estado indiferenciado, não organizado. Alguns pensadores desenvolverão a mesma noção com outros nomes: uma substância informada, um continuum, uma massa amorfa, 
uma nebulosa... Deleuze, por exemplo, a chamará em alguns momentos de substrato, em outros, de Aion: um espaço de tempo indeterminado, uma eternidade...

A 'realidade' natural é indeterminada num grau essencial para o fazer social; pode-se mover e mover-se, transportar e deslocar-se, cortar, juntar. (...) E esta indeterminação vai junto com uma determinação, com propriedades relativamente fixas e estáveis, e relações necessárias ou prováveis: se... então..., condição para fazer ser diferente aquilo que é. (Castoriadis, 1986, p. 400)

Ao Simbólico corresponde uma incisão, uma divisão que organiza (o cosmo, em oposição ao caos, na concepção grega) o que desse substrato passa então a se prestar à elaboração humana. Claro é que, nessas condições, do substrato só se pode dizer que é indiferenciado a partir do momento em que a diferença, o isolamento em elementos, é operada. Sem esse recorte que nos faz olhar para uma folha e classificá-la pelas suas características específicas em oposição às de outras folhas, essa folha pode ser.quase tudo ou até mesmo nada. No Real a nada equivale a quase tudo: o lugar donde se retira e, como um buraco, nunca se esgota, lugar, entretanto, que só se delineia a partir dessas circunscrições de campo a que corresponde cada retirada. A metáfora da escavação, utilizada pela psicanálise ao explorar estes conceitos, é bem apropriada: o côncavo na terra não existe enquanto não se começa a retirada da própria terra.

Entretanto, a simbolização aí operada, a nomeação que destaca os elementos não é feita sem que se criem significações. e sentidos para as coisas e para o mundo assim constituído: o próprio campo circunscrito é pura significação. O Imaginário corresponde, ao mesmo tempo, a tais significações, geradas a partir de circunscrições de campo, e ao seu conjunto, que vem constituir a realidade a ser vivida: o sentido de mundo assim produzido.

Lidamos, até agora, com dois entendimentos do termo imaginário, que são centrais ao presente texto. $O$ primeiro se explicita 
nas palavras de Lacan anteriormente citadas: o mundo, a realidade constituída, como ordem imaginária. Aqui o termo é aparentado a fictício, enquanto construção/apresentação do mundo e enquanto formação de uma imagem, uma visada de mundo. É também estrangeiro à noção de fictício enquanto consiste na realidade a ser vivida. O outro sentido diz respeito aos significados que se atrelam ao significante em situação imediata ao recorte por este operado. Laplanche e Pontalis referem-se a essa condição como "uma espécie de coalescência entre significante e significado". Tal conceito aponta não só para os significados específicos de uma palavra, ou de um recorte de campo, mas para um conjunto de significados que lhe aderem automaticamente e desenham um quadro, alocam valores e alinham condutas.

Tentemos exemplificar esta noção de coalescência pensando no cigarro e suas representações sociais. É certo que a palavra cigarro designa um objeto específico, designa uma forma contemporânea dada ao fumo e ao hábito. Ora, podemos reconhecer com facilidade que toda produção filmica, principalmente a hollywoodiana, durante a década de 40, 50 e 60 o vinculava à audácia, criatividade, inteligência, glamour... A partir da década de 80 , por conta de um projeto de esclarecimento sobre seus efeitos nocivos, as representações cinematográficas associam o cigarro às drogas em geral, à decadência social, a bandidos e a disfunções psíquicas. Estes são significados acoplados. Assemelham-se a uma nuvem envolvendo a palavra cigarro que, por sua vez, pode ser tanto uma coisa quanto outra. Como podemos ver, mesmo que concordemos com seu maleficio, o apontamento deste e a construção de significados nesta direção dependem muito mais de outros sentidos, já instalados como enfoque do mundo, do que do cigarro em sua hipotética essencialidade.

Este segundo entendimento de imaginário, que não deixa de supor o primeiro, nos remete também à constituição da realidade, porque ao conjunto de significados corresponde a criação de sentido, sentido de vida como direção de atitudes convenientes, que seguem seus tempos e lugares. A diferença desta segunda acepção, em relação à primeira, é somente de entorno, pois ela anota um 
processo de fixação de pontos a partir dos quais transbordam nossas fabulações.

A título de registro, porque não o exploraremos aqui, há em Lacan um terceiro entendimento do termo Imaginário. Relaciona-se ao fato de que o acesso à ordem simbólica é um advento datado, com sua ocorrência na primeira infância. Assim, os momentos que o precedem implicam uma experiência de mundo como continuum (infante/mãe) que é da ordem do imaginário em sua projeção de imagens mentais e em sua ficcionalidade, já que a conjunção total, suposta ou vivenciada como continuum, era, ela própria, somente imaginada.

De qualquer modo, há um equívoco, muitas vezes comentado, no que diz respeito ao estatuto do Imaginário para Lacan. Pelo fato de que este propõe uma antecedência lógica do significante sobre o significado, o Imaginário, sempre associado ao campo desenhado pelos significados, será compreendido como tendo sido colocado num $a$ posteriori. Torna-se importante assinalar então que, mesmo diante dessa antecedência, mantém-se a interdependência constitutiva das três instâncias, Real/Simbólico/Imaginário, que se implicam mutuamente a partir de uma única operação, de um único corte.

Au moment où je dis monde, n'aurais-je pás dî dire notre Réel, à cette condition qu'on s'aperçoive que lê monde ici comme représentatio dépend de la jonction de ces trois consistences d'ailleurs leur étant supposées. (Lacan, 21 janvier 1975, p.3)

Não há Real sem o recorte do Simbólico, pois o Real se define como aquilo sempre por recortar e tal recorte implica incidência sobre um campo que só se instala com o próprio recorte. Não há Simbólico que não arraste, ou gere Imaginário, afinal, a construção da realidade, do sentido do mundo é seu campo. E não há Imaginário, como sentido agregado, que não suponha o estatuto Imaginário da própria ordem simbólica.

O efeito total, que Deleuze associa à ordem imaginária, pode ser explicitado pela idéia, também por ele explorada, de estratificações 
(idéia em empréstimo à noção-de estratos em Hjelmslev) e de desterritorialização/terriotorialização, ou seja, de um consenso que constitui a realidade a ser vivida.

Na compreensão de Deleuze, a realidade construída, uma dobradura entre Simbólico, Real e Imaginário, tece camadas, estratificações que delineiam um modo de ver, pensar e viver o mundo. Claro que as estratificações estão sempre empurrando, cada vez mais perto e sempre mais distante (como no jogo de adivinhação: o que é, o que é?: quanto mais se tira maior fica?) uma zona de substância não-estratificada.

Cada camada apresenta uma visão de mundo e é nesta que os homens se reterritorializam, ou se fazem sucessivamente, depois de uma primeira desterriorialização da terra-mãe. É assim, por exemplo, que o homem, sua vida, seus saberes e poderes são um, conforme o mundo seja apresentado como geocêntrico ou heliocêntrico, a terra como plana ou esférica, o valor como teocêntrico ou antropocêntrico.

É por isso que, tomando a classificação peirceana de signo, Deleuze e Guattari pensam o signo ícone como signo de. reterritorialização, pois dele, como imagem, como visão apresentada, depende nossa formação de acordo com alguma estratificação; eles, os signos ícones, são as pontes que permitem a assimilação, de corpo e alma, a uma realidade específica (Deleuze e Guattari, v. 1, 1995, p.80).

O saci não é imaginário por sua materialidade não ter sido verificada: ele é tão imaginário quanto qualquer recorte. Como no da maçã, e sua comprovada materialidade, da qual, segundo nos dizem, se Newton fez bom uso, uma perda de paraíso se originou, importa 0 conjunto de atributos que lhe recobre. Maçã e saci, como tudo o mais, são simplesmente a realidade constituída, a cada tempo, a cada lugar: a tela e o manto do mundo a ser vivido.

O manto como metáfora nos reconduz ao trabalho do surrealismo com palavras e imagens, conceitos e teorias: as coisas do mundo. Um outro nome, não tão celebrado quanto o de Magritte, compõe-se com este movimento e trabalho e é invocado aqui. Tratase da artista Remedios Varo, nascida na Espanha em 1908 e falecida 
em 1963 no México, para onde imigrou durante a ocupação nazista. Remedios deixou-nos um quadro, concebido em 1961, sob o título Bordando el manto terrestre.

Nele há oito figuras em uma sala no interior de uma torre instalada acima do globo terrestre. Dentre estas. figuras, seis são tecelãs sentadas em frente a seus teares, aos quais se prendem linhas que se encontram num vaso situado no centro da sala. Uma figura de pé preside sobre este vaso e a cena. Manuseando uma haste, ela mexe as meadas contidas no vaso. Com a outra mão empunha um livro. No fundo da torre, em menor escala, uma figura acompanha os trabalhos e traz uma flauta à boca. Nas paredes da torre, em frente a cada tear, há fendas das quais sai um tecido que cai drapeando sobre o globo terrestre: de dobra em dobra, casas, paisagens, mares são abrigados.

Globo e manto, tecido e estratos, realidade e fiação, livro e ordenação, música e ritmo, imagem e noções, nome da obra e a própria obra: todos os elementos remetem às teorias e conceitos que acabamos de atravessar. Certamente o Imaginário está aí em todas as suas dimensões, em sua dobradura com o Real e o Simbólico.

Podemos aplicar a esta obra de Remedios Varo os mesmos termos utilizados por Michel Foucault ao comentar o quadro de Magritte, com o qual iniciamos nossa presente exploração, Ceci n'est pas une pipe:

Sept discours dans un seul énoncé. Mais il n'en fallait pas moins pour abattre la forteresse oú la similitude était prisonnière de l'assertion de ressemblance. (Foucault, 1973, p.54)

Sete discursos para mostrar, num mesmo enunciado, toda uma teoria: modo de apresentação que consiste na exploração das conexões entre as palavras e as coisas. Isto se firma no enunciado produzido pelo jogo entre a obra e seu nome. Ao discorrer, com palavras e imagens, sobre a tessitura do manto terrestre, o surrealismo dá pontos a seu modo, em forma de insistência, no bordado do manto do mundo. 


\section{Bibliografia}

BARTHES, R. 1970. "El efecto de realidad", in Lo verosímil. Buenos Aires: Editorial Tiempo Contemporáneo.

BOURDIEU, P. 2001. O poder simbólico. Rio de Janeiro: Bertrand Brasil.

BRETON, A. 1993. Manifestos do surrealismo. Lisboa: Salamandra.

CASTORIADIS, C. 1986. A instituição imaginária da sociedade. São Paulo: Paz e Terra.

DELEUZE, G. 1995 "Como reconhecer o estruturalismo". In História da filosofia, org. Châtelet, François. Lisboa: Publicações Dom Quixote.

. 1998a. Conversações. São Paulo: Editora 34.

de France.

1968. Différence et répétition. Paris: Presses Universitaires . 1998b. Lógica do sentido. São Paulo: Perspectiva.

DELEUZE, G. e GUATTARI, F. 1995a. Mil platôs. Capitalismo e esquizofrenia. v. 1. Rio de Janeiro: Editora 34.

Mil platôs. 1995b. Capitalismo e esquizofrenia. v. 2. Rio de Janeiro: Editora 34.

DRUMMOND de ANDRADE, C. 1945. "Procura da poesia" in A rosa do povo. São Paulo: José Olympio.

FOUCAULT, M. 1996. A ordem do discurso. São Paulo: Loyola.

1997. A vontade de saber. História da sexualidade. v. 1. Rio de Janeiro: Graal.

1995. As palavras e as coisas. São Paulo: Martins Fontes. Morgana.

LACAN, J. 1992. Escritos. São Paulo: Perspectiva.

. 1985. O seminário, livro 20, Mais, ainda. Rio de Janeiro: Jorge Zahar.

1974-1975. O seminário, livro 22, $R$. S. I. Cópia mimeografada. Paris.

LAPLANCHE e PONTALIS. 1996. Vocabulário da psicanálise. São Paulo: Martins Fontes. 